\title{
Hox is in the hair: a break in colinearity?
}

\author{
Denis Duboule ${ }^{1}$ \\ Department of Zoology and Animal Biology, University of Geneva, 1211 Geneva 4, Switzerland
}

During mammalian fetal development, axial structures acquire their specifications through the action of the Hox gene family of transcription factors (for review, see Kruml auf 1994). These are 39 such genes that are responsible for giving spatially restricted cues in a variety of embryonic derivatives, from the neural tube to the intestinal tract. In presomitic mesoderm, for example, level-specific qualitative as well as quantitative differences in HOX protein content will instruct the future sclerotomes on the morphological features that particuIar vertebrae should display. Therefore, it is important that the establishment of Hox expression domains be controlled faithfully, as slight mistakes in this process will lead to the misidentification of the corresponding structures, an effect that is often referred to as homeotic transformation. The complex coordination of this control is achi eved, in part, through a unique property of this gene family; genes are organized al ong the chromosome in a genomic sequence that reflects their time and place of activation during development. In mammals, there are four Hox clusters (A to D) and within each cluster, Hox genes located at the $3^{\prime}$ end are activated first and in anterior embryonic domains, whereas genes located at the $5^{\prime}$ end are transcribed subsequently and in more caudal areas. The spatial aspect of this intriguing correspondence, or "colinearity," was described originally by Lewis (1997) in Drosophila, and has since been observed in all animals exhibiting an anterior-to-posterior axial polarity. Interestingly, no clear exception to this rule has been reported to date. In this issue, however, Godwin and Capecchi present some surprising results from an elegant study of murine Hoxc13, a very posterior gene member of the HoxC complex. Unexpectedly, Hoxc13 is expressed in hair follicles throughout the body as well as in vibrissae and in the tongue, that is, at locations much too anterior for the "genomic position" of this gene. Does Hoxc13 violate the code of colinearity?

Hox genes members of the most posterior groups of paralogy, from group 9 to 13, are all related to the Drosophila gene Abdominal-B (A bdB; Izpisua-Belmonte et al. 1991). Expression studies as well as gene knock outs have reveal ed that Hoxd13 and Hoxal3 are required for the development of the most posterior structures in the trunk, such as the sacrocaudal vertebral transition, the anal sphincter, the external genitalia, as well as the uro-

1E-MAIL Duboule@sc2aunigeCH; FAX 41227026795. genital system and associated glands (Dollé et al. 1993; Davis and Capecchi 1996; Kondo et al. 1996, 1997; Podlasek et al. 1996; Warot et al. 1997). The expression of the two other members of this paral ogy group, Hoxb13 (Zeltser et al. 1996) and Hoxc13 (Peterson et al. 1994), suggested that a similar posterior restriction would be observed in the phenotypes of mice carrying null alleles of these genes. The generation of mice lacking Hoxc13 function confirmed that alterations of the vertebral column were restricted to the tail, where homeotic transformations of caudal vertebrae toward a more anterior morphology were observed (Godwin and Capecchi 1997). Surprisingly however, homozygous animals lacked vibrissae at birth and subsequently showed a strong defect in brittle hair leading to al opecia, that is, the absence of emerging hairs, although hair follicles seemed to form normally. Because the inactivation strategy invol ved the insertion of lac $Z$ reporter sequences in-frame with the Hoxc13 coding sequences, a detailed expression study allowed a perfect correlation to be established between this unexpected phenotype and Hoxcl3 transcription specificity during fetal skin development.

Hox is in the hair

The morphogenesis of vertebrate skin involves interactions between the dermis and the epidermis, a mesenchyme and an epithelium, respectively. Various regionspecific appendages are produced by this organ such as vi brissae and pelage (body coat) hairs. Recombination experiments by Dhouailly (1977) have shown that this regional specificity is linked mainly to the origin of the dermis. The morphogenetic steps in the devel opment of vibrissae and pelage hair follicles are similar to each other and have been classified by Hardy (1968; see al so Kantzler et al. 1994). Differentiation of the facial integument begins at day 11.5 (E11.5), whereas body skin differentiation does not occur before E14.5. Initially, a condensation of the dermis appears together with a thickening of the epithelial layer. Epidermal cells then proliferate to produce hair pegs and keratinocytes will differentiate to form the hair follicles followed by the emergence of hair shafts at E18. Although the expression of Hoxc13 was not detected in dermal papillae, the use of various markers such as a type II epidermal keratin (K2.6), which together with its partner $\mathrm{K} 1.16$ characterizes proliferative keratinocytes, al lowed the detection of $\beta$-galactosidase ( $\beta$-gal) activity in all hair follicles (God- 
win and Capecchi 1997), in those cells of the companion layer expressing the K2.6 keratin (Rothnagel and Roop 1995). Interestingly, this single cell layer was still present in Hoxc13 homozygous mutant animals, indicating that this function was not required for the production or maintenance of these cells. Hoxc13 transcription was then detected in rapidly dividing keratinocytes in the hair bulb as well as in the hair shaft, concomitant with the expression of high sulfur proteins (Lynch et al . 1986).

$\beta-G a l$ activity was also scored in the filiform papillae of the tongue, structures that are specific for the dorsal surface of the tongue and thought to resemble hair follicles due to the presence of papillae, a cross-reactivity with an antibody against differentiating hairs (Dhouailly et al . 1989), and to the expression of several genes such as those for hair keratin intermediate filaments and trichohyalin. In these filiform papillae, Hoxc13 was expressed as early as E17 in a region closely corresponding to that of $\mathrm{mHa} 3$ hair keratin expression (Winter et al. 1994). Such a widespread expression of Hoxc13 in these cutaneous appendages correlated nicely with a series of striking phenotypes affecting all of these different structures such as a lack of protruding vibrissae and abnormal nails. Surviving mice were hairless, and essentially all hair types described so far (Sundberg and Hogan 1994) were affected by this mutation. Although pelage hairs formed, they were fractured at the skin surface, so that some rare hairs could be detected in regions protected from rubbing. Likewise, filiform papillae of the tongue were broken. Even though no particular type of keratin was shown to be affected in mutant hair follicles, such a phenotype strongly suggested a function for Hoxc13 in controlling the production of structural proteins necessary for the differentiation of skin appendages. The wide distribution of these phenotypic alterations genetically demonstrates the ontogenetic relationships between the different skin appendages.

\section{A violation of colinearity?}

Expression of Hox genes in developing skin has been reported previously (Chuong et al. 1990; Bieberich et al. 1991; Kantzler et al. 1994). However, an anterior-posterior restriction in the extent of expression along the rostrocaudal axis was observed. In the case of the closely related Hoxd13 gene, expression was reported in epithelial-derived portions of hair follicles but only in the most caudal part of the skin. In this case, the expression boundary was indistinguishable from those of Hoxd9 and Hoxd11, which were also expressed in these integuments (Kantzler et al. 1994). What makes the Godwin and Capecchi report of particular interest, in addition to the functional aspect discussed above, is that all hair follicles are involved, regardless of their positions along the body axis. Godwin and Capecchi emphasize that such an observation apparently is at odds with the rule of spatial colinearity, which would have predicted an expression of Hoxc13 in caudal hair follicles only (see Fig. 1). However, a slightly different view of these results suggests that if a violation of colinearity is observed, it
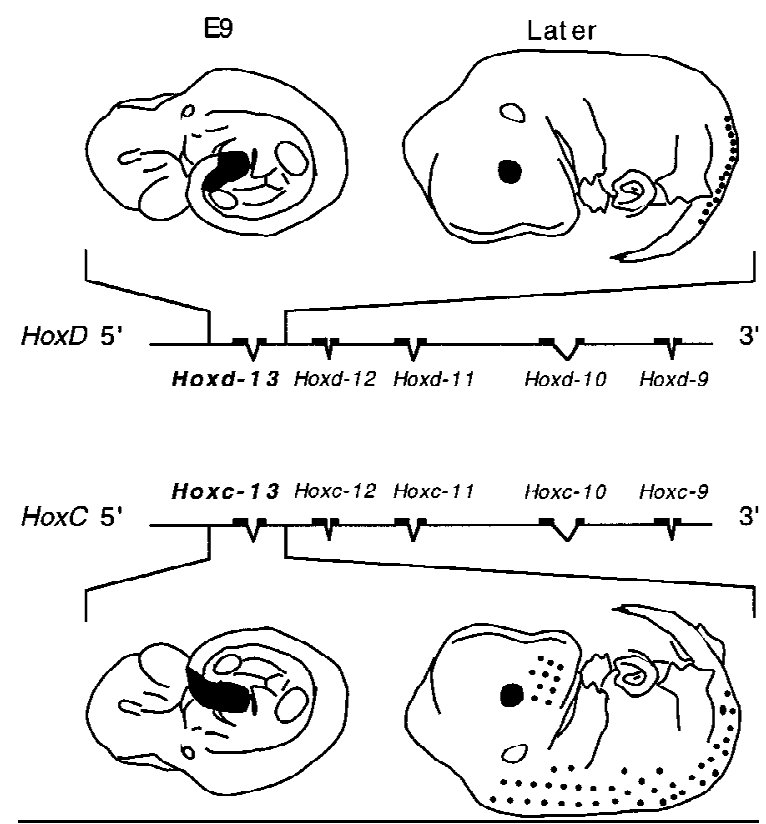

Figure 1. Schematic representation of the expression patterns of the two paralogous genes, Hoxd13 and Hoxc13, at different devel opmental stages. In the middle, the posterior halves of the HoxD (top) and HoxC (bottom) complexes are shown with the five genes related to the Drosophila AbdB gene (from group 9 to 13). The expression profiles of these two genes, either at E9 (left) or at a later devel opmental stage (right), are depicted. (Left) Both genes show an early activation (as represented in black) in the region of the tail bud, thus respecting colinearity. On the right, a clear difference appears in hair follicles. Although Hoxd13 expression is restricted to the caudal part (black dots), Hoxc13 is expressed there up to anterior regions, as well as in the vibrissae. Other areas of expression are not shown. The two diagrams on the right merely illustrate a general devel opmental stage (see the text, and Godwin and Capecchi 1997, for precise details). Similarly, the labeled hair follicles do not reflect a genuine pattern but indicate the absence of posterior restriction in Hoxc13.

may not be so serious and, most importantly, does not imply a revision of this concept. In particular, the original colinear mechanism, that is, the process by which Hox genes are sequentially acti vated temporally and spatially as gastrulation proceeds, is clearly respected. During early development, Hoxc13 expression was as anticipated, appearing rather late in the growing tail bud, that is, with a strict posterior restriction (Fig. 1; Peterson et al. 1994; Godwin and Capecchi 1997). In this respect, therefore, colinearity as defined originally to apply to vertebrates (Gaunt et al. 1988; Duboule and Dollé 1989; Graham et al. 1989) is not transgressed by Hoxc13, and the subsequent widespread expression of this gene in hair follicles is not connected to its early colinear regulation.

Such an unexpected expression pattern could be best explained by the functional recruitment of this gene, in the course of evolution, for achieving some additional function in hair follicles such as controlling the production of structural proteins, as proposed by Godwin and 
Capecchi (1997). The cl ose linkage of the keratin-2 complex to the HoxC locus on mouse chromosome 15 (Hart et al. 1992) may be indicative of how some Hox genes became involved in hair development, through the potential sharing of a hair follicle-specific gl obal regulatory control. The phenotype indicates that proteins involved in the solidity of the hairs could be under the control of Hoxc13, such as some high sulfur proteins associated with keratin intermediate filaments (Lynch et al. 1986). Hox cream may cure bal dness.

An alternative possibility is that Hox genes are expressed in hair follicles to establish a polarity in these structures. In this view, hair follicles would be considered as axial structures and would then require the Hox information to differentiate proximal from distal aspects. In this case, a break in colinearity would not be unexpected. Such a situation has al ready been observed with Hoxd13 and Hoxa13, two genes strongly expressed in forelimbs, that is, at more anterior positions than their transcript domains in the trunk (Dollé et al. 1993; Haack and Gruss 1993). In fact, it is shown here that Hoxc13 is also expressed in forelimbs; hence the proposed break in colinearity may not be restricted to hair follicles. In support of this view, Hoxcl3 seems to be required for one of the last steps in hair differentiation (Godwin and Capecchi 1997), much in the sameway that Hoxd13 and Hoxa13 are involved in the last steps of limb pattern formation (Fromental-Ramain et al. 1996). However, it is unlikely that Hox gene expression in the course of hair devel opment follows the same strategy as for either the trunk or the appendicular axes. In the case of Hoxc8, another member of the HoxC complex, although expression in the epidermal component of the skin was also scored, it was found only at restricted body levels and two gl abrous zones were observed in the lumbar region of mice homozygous for a null allele of this gene (Kanzler et al. 1994). In addition, Hoxc8 was reported to be transcribed in the dermal papillae, in marked contrast to Hoxc13. This finding reinforces the suggestion that the function of Hoxc13 during hair development may not reflect a general feature of most HoxC complex genes. Furthermore, during skin development, posterior Hoxd genes are expressed in caudal areas exclusively, indicating that whatever their function is in the morphogenesis of integuments, this function is not required throughout the body, unlike what is now reported for Hoxc13. Hoxwise, hair follicles do not seem to share the properties of genuine appendicular structures such as the limb and genital buds.

\section{The Hox veto}

It is likely that a closer examination of Hox gene expression and function will reveal many target tissues and organs in adults, in which particular HOX proteins will be necessary, regardless of their original embryonic, colinear distribution. This is to be expected when considering the high degree of "recycling" of control genes, as judged by their commonly observed multiple sites of expression and plei otropic effects (for review, see Gerhart and Kirschner 1997). One might even wonder why, during the course of evolution, such a reservoir of Hox transcription factors, with a rather large spectrum of DN A binding specificities, has not been used more frequently as a source of material for early devel opment. This question is particularly valid for early (pregastrulation) embryonic devel opment. Indeed, Hox function seems not to be required until about day 7 postfertilization, the time at which the anterior Hox genes first become activated. It is puzzling that the many Hox genes that are involved in processes unrelated to their original axial-specification function (e.g., in blood cells or during spermatogenesis) achieve these additional functions only after their most ancestral task is over (i.e., after gastrulation), whereas none of these genes was ever reported to affect embryonic development before their colinear activation. It is as if the functional recruitment of Hox genes in vertebrates had been made impossible for a function occurring before axial specification.

One possible reason for this strange observation may rely directly upon the mechanistic basis of colinearity. It has been proposed that vertebrate Hox complexes, early in development, are in a closed configuration and that the colinear activation of these genes follows their progressive accessibility through a linear "opening" of the complexes (van der Hoeven et al. 1996). In such a view, a functional recruitment of a Hox gene for an earlier function, for instance, mesoderm induction, would necessitate the premature opening of the complex during development; hence, the loss of this critical property. This situation would be natural ly detrimental to the embryo as posterior HOX proteins would antagonize the functions of the anterior genes (Duboule and Morata 1994). Therefore, the mechanism behind colinearity may represent a strong functional veto to gene co-option. In contrast, diptera probably activate their homeotic genes from fully accessible complexes, as a result of the action of upstream genes al ready regionally expressed in the embryo (Lawrence 1992). Consequently, Drosophila genes required for early development are allowed to be interspersed among homeotics, such as fushi tarazu and bicoid in the Drosophila Antennapedia complex (e.g., Kaufman et al. 1990). In this context, an authentic violation of colinearity in vertebrates would require the expression of any Hox gene either before its normal time of activation or at an unusual ly anterior position at gastrulation. Until such expression can be documented, the rule will stand.

\section{Acknowledgments}

I thank D. Dhouailly, M. Kumar, and T. Kondo for their corrections and suggestions.

\section{References}

Bieberich, C.J., F.H. Ruddle, and K.S. Stenn. 1991. Differential expression of the Hox3.1 gene in adult mouse skin. Ann. N.Y. Acad. Sci. 642: 346-353.

Chuong, C.-M., G. Oliver, S.A. Ting, B.G. Jegalian, H.M. Chen, 
and E.M. de Robertis. 1990. Gradients of homeoproteins in devel oping feather buds. Development 110: 1021-1030.

Davis, A.P. and M.R. Capecchi. 1996. A mutational analysis of the 5' HoxD genes: Dissection of genetic interactions during limb development in the mouse. Development 122: 11751185.

Dhouailly, D. 1977. Regional specification of cutaneous appendages in mammal. Wilhelm Roux's Arch. Dev. Biol. 181: 310.

Dhouailly, D., C. Xu, M. M anabe, A. Schermer, and T.-T. Sun. 1989. Expression of hair-related keratins in a soft epithe lium: Subpopulations of human and mouse dorsal tongue keratinocytes express keratin markers for hair-, skin-, and oesophageal-types of differentiation. Exp. Cell Res. 181: 141158.

Dollé, P., A . Dietrich, M . LeM eur, T. Schimmang, B. Schuhbaur, P. Chambon, and D. Duboule. 1993. Disruption of the Hoxd13 gene induces local ized heterochrony leading to mice with neotenic limbs. Cell 75: 431-441.

Duboule, D. and P. Dollé. 1989. The structural and functional organization of the murine $\mathrm{HOX}$ gene family resembles that of Drosophila homeotic genes. EMBO J. 8: 1497-1505.

Duboule, D. and G. Morata. 1994. Colinearity and functional hierarchy among genes of the homeotic complexes. Trends Genet. 10: 358-364.

Fromental-Ramain, C., X. Warot, N. M essadecq, M. Lemeur, P. Dollé, and P. Chambon. 1996. Hoxa-13 and Hoxd-13 play a crucial role in the patterning of the limb autopod. Development 122: 2997-3011.

Gaunt, S.J., P.T. Sharpe, and D. Duboule. 1988. Spatially restricted domains of homeo-gene transcripts in mouse embryos: Relation to segmented body plan. Development (Suppl.): 71-82.

Gerhart, J. and M. Kirschner. 1997. Cells, embryos and evolution. Blackwell Science, $\mathrm{M}$ alden, $\mathrm{MA}$.

Godwin, A.R. and M.R. Capecchi. 1997. Hoxc13 mutant mice lack external hair. Genes \& Dev. (this issue).

Graham, A., N. Papal opulu, and R. Krumlauf. 1989. The murine and Drosophila homeobox gene complexes have common features of organization and expression. Cell 57: 367-378.

Haack, H. and P. Gruss. 1993. The establishment of murine Hox-1 expression domains during patterning of the limb. Dev. Biol. 157: 410-422.

Hardy, M.H. 1968. Glandular metaplasia of hair follicles and other responses to vitamin A excess in cultures of rodent skin. J. Embryol. Exp. Morphol. 19: 157-180.

Hart, C.P., J.G. Compton, S.H. Langley, L. Hunihan, K.P. LeClair, A. Zelent, T.H. Roderick, and F.H. Ruddle. 1992. Genetic linkage analysis of the murine developmental mutant velvet coat ( $\mathrm{Ve}$ ) and the distal chromosome 15 developmental genes Hox3.1, Rar-gamma, Wnt-1 and Krt-2. J. Exp. Zool. 263: 83-95.

Izpisua-Belmonte, J.-C., H. Falkenstein, P. Dollé, A. Renucci, and D. Duboule. 1991. Murine genes related to the Drosophila Abd-B homeotic gene are sequentially expressed during devel opment of the posterior part of the body. EMBO J 10: 2279-2289.

Kantzler, B., J.-P. Viallet, H. LeM ouellic, E. Boncinelli, D. Duboule, and D. Dhouailly. 1994. Differential expression of two different homeobox gene families during mouse tegument morphogenesis. Int. J. Dev. Biol. 38: 633-640.

Kaufman, T.C., M.A. Seeger, and G. Olsen. 1990. M olecular and genetics organisation of the Antennapedia gene complex of Drosophila melanogaster. In Advances in genetics: Genetic regulatory hierarchies in development (ed. J.G. Scandalios and T.R.F. Wright), Vol. 27, pp. 309-362. Academic Press,
San Diego, CA.

Kondo, T., P. Dollé, J. Zakany, and D. Duboule. 1996. Function of posterior Hoxd genes in the morphogenesis of the anal sphincter. Development 122: 2651-2659.

Kondo, T., J. Zakany, J.W. Innis, and D. Duboule. 1997. Of fingers, toes and penises. Nature 390: 29.

Krumlauf, R. 1994. Hox genes in vertebrate devel opment. Cell 7: 191-201.

Lawrence, P.A. 1992. The making of a fly. Blackwell Scientific Publications, Oxford, UK.

Lewis, E.B. 1997. A gene complex controlling segmentation in Drosophila. Nature 276: 565-570.

Lynch, M.H., W.M. O'Guin, C. Hardy, L. Mak, and T.-T. Sun. 1986. Acidic and basic hair/nail (hard) keratins: Their localisations in the upper cortical and cuticle cells of the human hair follicle and their realationship to soft keratins. J. Cell Biol. 103: 2593-2606.

Peterson, R.L., T. Papenbrock, M.M. Davda, and A. Awgulewitsch. 1994. The murine Hoxc cluster contains five neighbouring AbdB related genes that show unique spatially coordinated expression in posterior embryonic subregions. Mech. Dev. 47:253-260.

Podlasek, C.A., D. Duboule, and W. Bushman. 1997. Male accessory sex organ morphogenesis is altered by loss of function of Hoxd-13. Dev. Dynam. 208: 454-465.

Rothnagel, J.A. and D.R. Roop. 1995. Hair follicle companion layer: Reacquainting and old friends. J. Invest. Dermatol. 101: 505-555.

Sundberg, J.P. and M.E. Hogan. 1994. Hair types and subtypes in the laboratory mouse. In Handbook of mouse mutations with skin and hair abnormalities (ed. J.P. Sundberg), pp. 5768. CRC Press, Boca Raton, FL.

van der Hoeven, F., J. Zákány, and D. Duboule. 1996. Gene transpositions in the HoxD complex reveal a hierarchy of regulatory controls. Cell 85: 1025-1035.

Warot, X., C. Fromental-Ramain, V. Fraulob, P. Chambon, and P. Dollé. 1997. Gene dosage-dependent effects of the Hoxa13 and Hoxd-13 mutations on morphogenesis of the terminal parts of the digestive and urogenital tracts. Development 124: 4781-4791.

Winter, H., P. Siry, E. Tobiasch, and J. Schweizer. 1994. Sequence and expression of murine type I hair keratins $\mathrm{mHa} 2$ and mHa3. Exp. Cell Res. 212: 190-200.

Zeltser, L., C. Desplan, and N. Heintz. 1996. Hoxb-13: A new Hox gene in a distant region of the HOXB cluster maintains colinearity. Development 122: 2475-2484. 


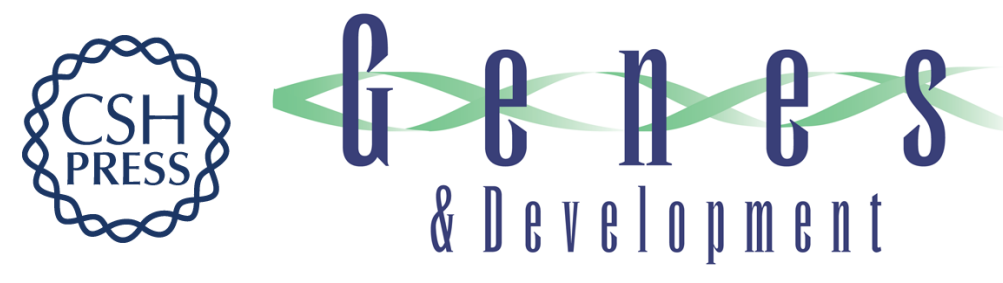

\section{Hox is in the hair: a break in colinearity?}

Denis Duboule

Genes Dev. 1998, 12:

Access the most recent version at doi:10.1101/gad.12.1.1

References This article cites 26 articles, 7 of which can be accessed free at: http://genesdev.cshlp.org/content/12/1/1.full.html\#ref-list-1

License

Email Alerting Receive free email alerts when new articles cite this article - sign up in the box at the top Service right corner of the article or click here.

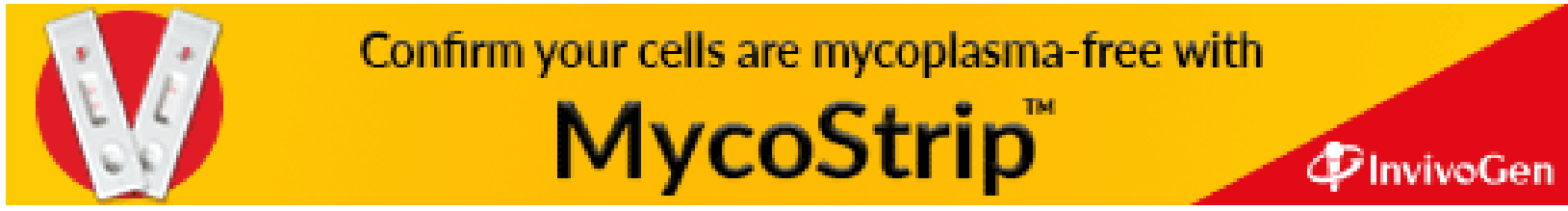

